L. Francis Xavier* and Paramasivam Suresh

\title{
Drilling studies on the prepared aluminum metal matrix composite from wet grinder stone dust particles
}

DOI 10.1515/secm-2016-0040

Received February 9, 2016; accepted September 27, 2016; previously published online November 17, 2016

Abstract: The demand for high-performance and costeffective composite materials is gaining attention in today's competitive world. In this work, an attempt has been made to prepare low-cost reinforced aluminum metal matrix composite by reinforcing $10 \%$ and $20 \%$ weight fractions of wet grinder stone dust (WSD) particles, an industrial waste produced during stone dressing operation in the wet grinder manufacturing industry. As drilling is one of the major machining operations carried out in industries, the prepared composite materials are subjected to drilling studies using carbide, TiN-coated carbide, and HSS drills of $5 \mathrm{~mm}$ diameter under dry conditions. The major concern with the machining of composites is the extreme tool wear. Tool wear is a very important and challenging task for manufacturing engineers because it has adverse affects on the product quality and increases the production cost. Hence, there is a need to identify the factors that have most significant influence on the tool wear. In this work, the Taguchi-based design of experiments and analysis of variance were used to determine the optimal cutting parameters and to analyze their effects on thrust force, torque, and tool wear. Multivariable linear regression analysis was also employed to determine the correlations between the factors and the response, namely, thrust force, torque, and tool wear. Finally, a confirmation test was conducted to validate the Taguchi optimization method. From the experimental results, feed rate was identified as the dominant factor influencing the thrust force and spindle speed was identified as the significant factor influencing the torque. Thrust force, torque, and tool wear were found to increase with the increase in the reinforcement content irrespective of the drill used for the investigation.

*Corresponding author: L. Francis Xavier, Department of Mechanical Engineering, Karpagam College of Engineering, Coimbatore 641032, Tamil Nadu, India, e-mail: Ifxsavier82@gmail.com

Paramasivam Suresh: Department of Mechanical Engineering, Karpagam College of Engineering, Coimbatore 641032, Tamil Nadu, India
Keywords: industrial waste; multivariable linear regression analysis; Taguchi method; thrust force; tool wear; torque.

\section{Introduction}

Aluminum metal matrix composites (AMMC) are extensively used in many industrial applications such as defense, aerospace, automobile, and sports because of many admirable properties such as high strength, high stiffness, high thermal conductivity, very good wear, and corrosion resistance. The major concern with the machining of AMMC is the extreme tool wear caused by the abrasive action of the reinforced particles, which leads to high machining cost [1-3]. Generally, the drilling process is carried out in the last stage before assembly. It has been reported that nearly one third of the metal removal process performed in industries is drilling operation [4-8].

Tool wear is a very important and challenging task for manufacturing engineers as wear on drill affects the hole quality, increases the surface roughness and production cost, and decreases the tool life [9-11]. Tool wear depends on the type of tool material, cutting speed, feed rate, lubricant selected, and work material [11, 12]. Thus, to improve the productivity and reduce the machining cost, it is necessary to understand the reason for reduced tool life [13]. Tool wear can be measured by two methods, namely, direct and indirect methods [14, 15]. The indirect method estimates tool wear by measuring the cutting force signals, acoustic emission, vibration, and current [12, 14], whereas the direct method uses optical methods to estimate the tool wear $[14,16]$. Between the two methods, researchers prefer to use the indirect method to measure the tool wear because the indirect method allows the continuous monitoring of the tool condition to estimate tool wear; this is not possible with the direct method because the wear land is not visible during the cutting operation $[16,17]$.

In this work, AMMC was prepared by reinforcing $10 \%$ and $20 \%$ weight fractions of wet grinder stone dust (WSD) particles, an industrial waste by-product generated during the processing of quarry stone. The most important 
raw material used for the manufacture of a wet grinder is the rough stone. The dust particles formed during the machining process of the quarry stone retain the chemical composition and characteristics of the rock. Generally, these rock dust particles are either used as land fillers or in the manufacturing of various construction admixtures and plasters.

In this work, Al6063 alloy is selected as the base matrix alloy to prepare the AMMC, because it is widely used in industries due to its desirable properties such as corrosion resistance, good extrudability, weldability, and high-quality surface finish. Al6063 alloy is used in various applications such as heat sink sections, flexible assembly systems, special machinery elements, railings, truck and trailer flooring, radiator, and other heat exchanger applications.

The Taguchi design of experiments and analysis of variance (ANOVA) were applied to analyze the effectiveness of the parameters to minimize the thrust force, torque, and tool wear. Multivariable linear regression analysis was also employed to determine the correlations between the factors and the response (thrust force, torque, and tool flank wear).

\section{Materials and methods}

Al6063 alloy, which is used as the base matrix material in preparing the composite, has the following chemical composition (\%): Si 0.303, Fe 0.071, Cu 0.0050, Mn 0.0759, Mg 0.529, Cr 0.0037, Ni 0.014, Zn 0.025, Ti 0.0151, Ca 0.0146 , and $\mathrm{Al} 98.94$. The composite was prepared by reinforcing $10 \%$ and $20 \%$ of WSD particles under $45 \mu \mathrm{m}$ grain size as shown in Figure 1. The EDAX test report of the WSD particles as shown in Figure 2A reveals the presence of $\mathrm{Si}, \mathrm{Ca}, \mathrm{Fe}, \mathrm{Al}, \mathrm{Mg}$, and $\mathrm{Na}$ as its major elements. Table 1 shows the physical properties of the WSD particles. The density of the WSD particles was found to be $2.2 \mathrm{~g} / \mathrm{cm}^{3}$. In Figure 2B, the crystal shape of the WSD was found to be spherical and irregular in shape. The WSD particles are gray in color, and the specific gravity was found to be $2.4 \mathrm{~g} / \mathrm{cm}^{3}$.

The composites with $10 \%$ and $20 \%$ weight fractions of WSD particles were prepared by a two-step stir casting process. Initially, the WSD particles were preheated up to $250^{\circ} \mathrm{C}$ to remove the moisture content and improve its wettability with the base matrix alloy. The Al6063 alloy was charged into the crucible and heated to a temperature of $750^{\circ} \mathrm{C}$ to melt the alloy. Then, the liquid alloy was allowed to cool until it attains semisolid state at a temperature of about $600^{\circ} \mathrm{C}$. The preheated WSD particles along with 0.1

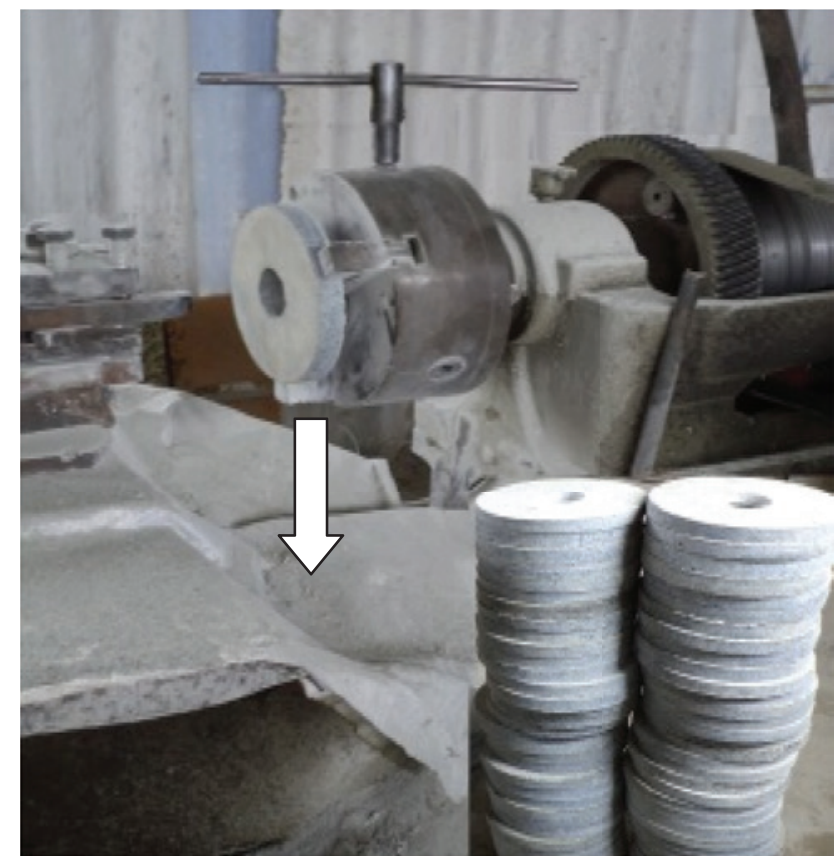

Figure 1: WSD particles indicated as arrows.

$\mathrm{wt} \%$ magnesium were added into the melt and stirred at a speed of $400 \mathrm{rpm}$ for $15 \mathrm{~min}$. The temperature was raised to $850^{\circ} \mathrm{C}$ and a second stirring was performed for $15 \mathrm{~min}$. Finally, the prepared composite samples were poured into the prepared sand moulds.

\subsection{Microstructure and mechanical properties}

Figure 2B and $\mathrm{C}$ shows the scanning electron microscopy (SEM) image and specific surface area of the WSD particles. The microstructure of the prepared composites is shown in Figure 3A and B under $\times 100$ magnification. The SEM result shows the distribution of the reinforced particles as reasonably uniform. The $\mathrm{CaCO}_{3}$ present in the WSD particles react with the molten aluminum melt to form various solid phases such as $\mathrm{CaO}, \mathrm{Al}_{2} \mathrm{O}_{3}$, and $\mathrm{Al}_{4} \mathrm{C}_{3}$.

Figure 4A and $\mathrm{B}$ shows the EDAX test report of the prepared samples. The spectrum of both $10 \%$ and $20 \%$ of WSD particles shows the presence of $\mathrm{Al}, \mathrm{O}$, and $\mathrm{C}$ elements, which indicates the presence of $\mathrm{Al}_{2} \mathrm{O}_{3}$ and $\mathrm{Al}_{4} \mathrm{C}_{3}$ particles in the aluminum matrix. From Figure $3 \mathrm{~A}$ and $\mathrm{B}$, it is clear that $\mathrm{Al}_{2} \mathrm{O}_{3}$ particles are shown as small spherical white dots and $\mathrm{Al}_{4} \mathrm{C}_{3}$ particles are shown as dark brown crystals distributed as reasonably uniform in the base matrix. 

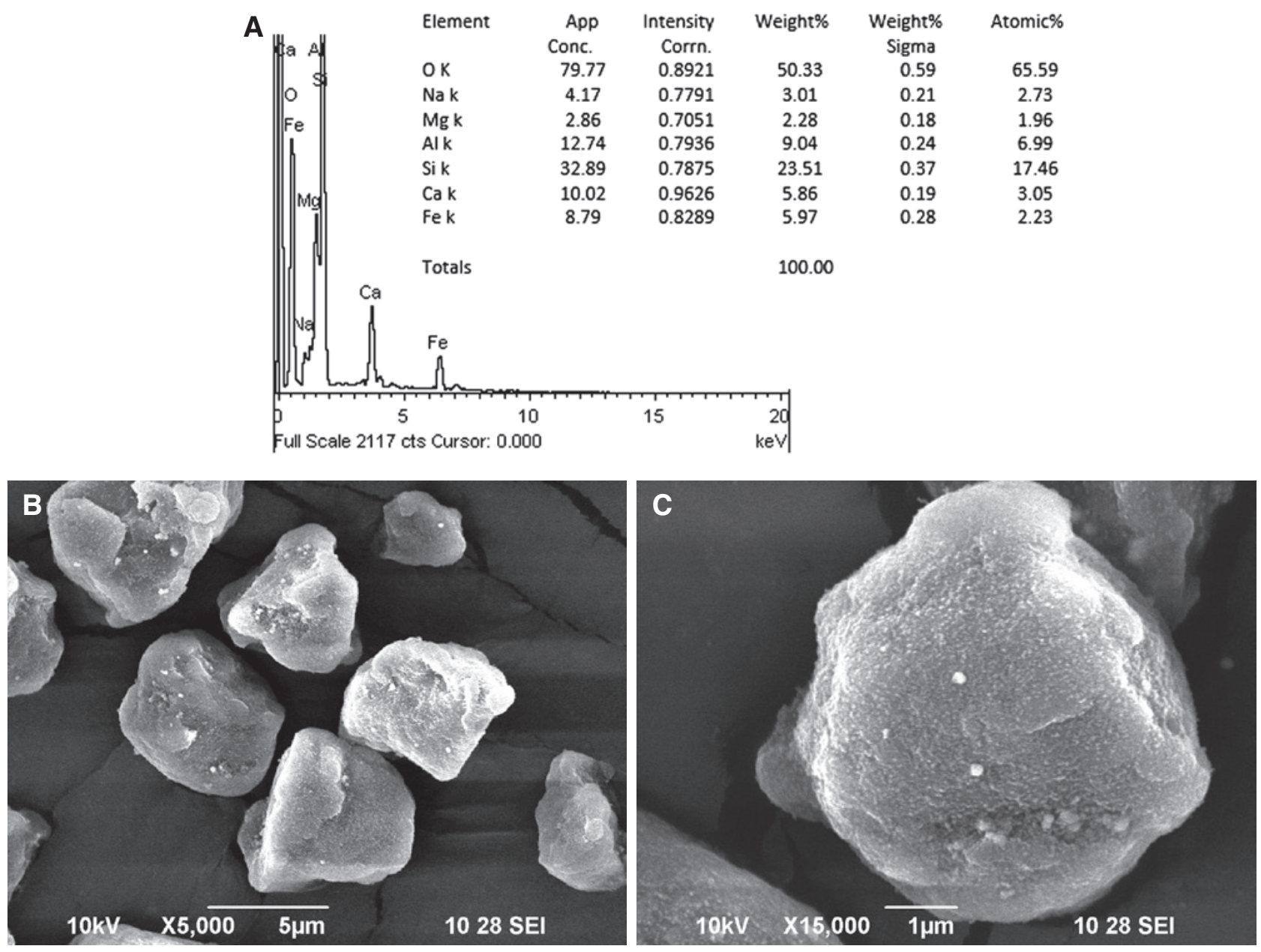

Figure 2: (A) EDAX test report of WSD particles, (B) SEM of the WSD particle and (C) specific surface area of the WSD particle.

Table 1: Physical properties of WSD particles.

\begin{tabular}{ll}
\hline Color & Grey \\
Density & $2.2 \mathrm{~g} / \mathrm{cm}^{3}$ \\
Surface area & $0.30-0.60 \mathrm{~m}^{3} / \mathrm{g}$ \\
Specific gravity & $2.4 \mathrm{~g} / \mathrm{cm}^{3}$ \\
Crystal shape & Spherical/irregular \\
\hline
\end{tabular}

The prepared samples were subjected to hardness and tensile test to study their mechanical properties. According to the hardness test results, the average hardness of the specimens prepared by reinforcing $10 \%$ and $20 \%$ of WSD were measured as 62 and 74 BHN, respectively. The hardness value of the prepared composites was found to be higher than that of the base matrix-Al6063 alloy. The increase in the hardness of the prepared composite can be attributed to the presence of hard reinforcements such as $\mathrm{Al}_{2} \mathrm{O}_{3}$ particles in the WSD particles. Table 2 shows the results of the mechanical properties such as yield strength, ultimate tensile strength, and elongation (\%) of the prepared samples. It can be seen from Table 2 that the yield strength and tensile strength of the prepared composites are higher than that of the base matrix. The yield strength and tensile strength value increase with the increase in the reinforcement content. The highest tensile strength value was obtained for the composite prepared by reinforcing $20 \%$ of WSD particles.

Increasing the reinforcement content from $10 \%$ to $20 \%$ increases the hardness and tensile strength of the composites but reduces its ductility, which coincides with previous findings $[18,19]$. This may be due to the poor bonding and agglomeration of the reinforced particles in the aluminum matrix. On the contrary, decreasing the reinforcement content $<10 \%$ has poor uniform distribution of the reinforcement particles. Thus, in this work, $10 \%$ and $20 \%$ of the reinforcement contents were used to prepare the composite. 



Figure 3: (A) SEM of sample 1 AL6063/10\% WSD powder and (B) SEM of sample 2 AL6063/20\% WSD powder.

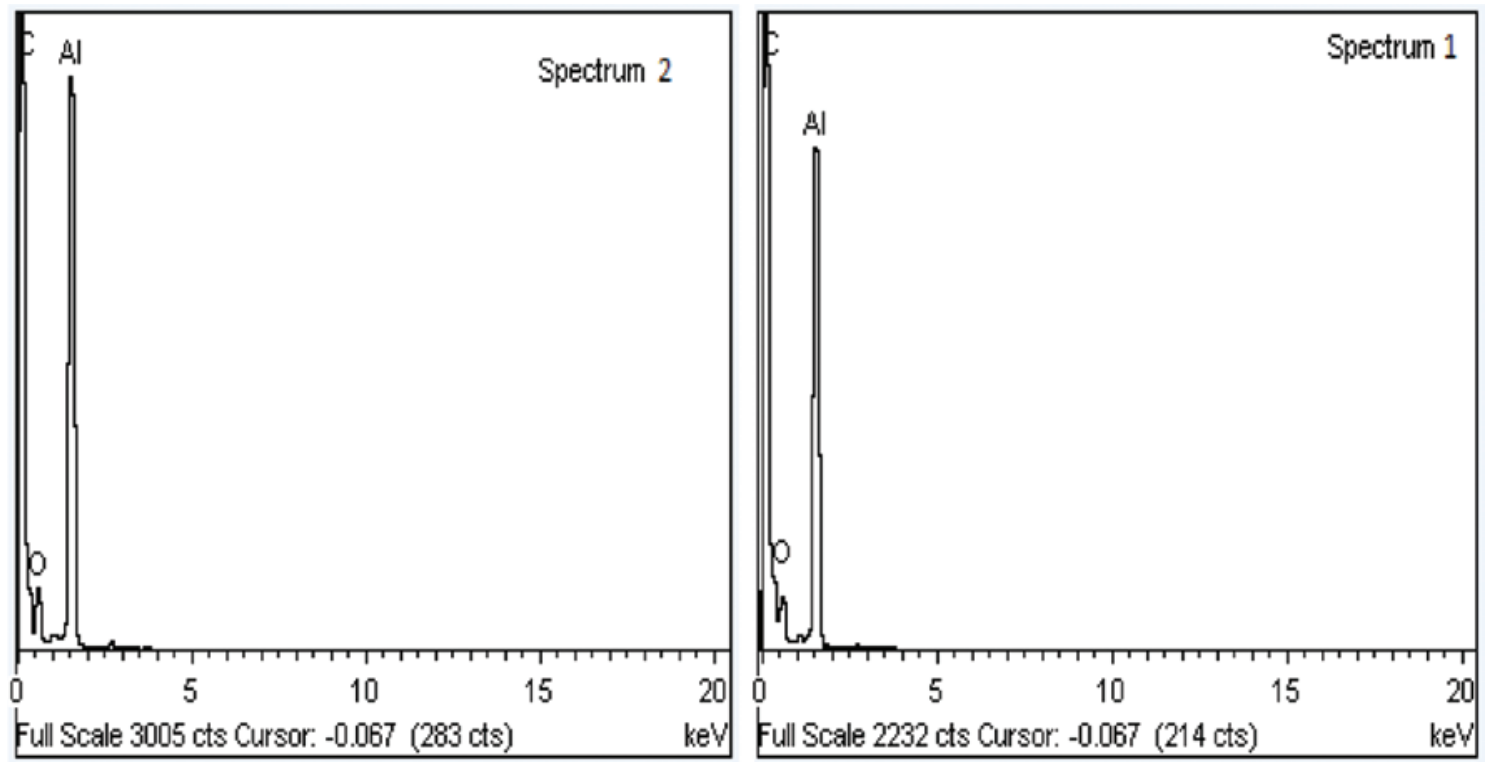

Figure 4: (A) EDAX test report of sample 1 and (B) EDAX test report of sample 2.

Table 2: Mechanical properties of the prepared composites and Al6063 alloy (T1 temper condition).

\begin{tabular}{|c|c|c|c|c|c|}
\hline SI no. & Material & $\begin{array}{r}\text { Hardness value } \\
\text { (BHN) }\end{array}$ & $\begin{array}{r}\text { Yield strength } \\
(\mathrm{MPa})\end{array}$ & $\begin{array}{l}\text { Ultimate tensile } \\
\text { strength (MPa) }\end{array}$ & Elongation (\%) \\
\hline 1 & Al6063 alloy & 43 & 67 & 131 & 13.5 \\
\hline 2 & $\mathrm{Al} 6063+10 \% \operatorname{Prm}$ & 62 & 114 & 153 & 7.83 \\
\hline 3 & Al $6063+20 \%$ Prm & 74 & 132 & 166 & 5.80 \\
\hline
\end{tabular}




\subsection{Experimental procedure and optimization using the Taguchi technique}

In this work, the drilling test was conducted under dry cutting conditions on a conventional vertical drilling machine. The machining samples were prepared in the form of $100 \times 55 \times 15 \mathrm{~mm}$ rectangular plates. The rectangular plate was then fixed firmly to a fixture attached to the dynamometer that was mounted on the table. Figure 5A shows the experimental set-up used for converting the drilling force imparted on the work piece into thrust force and torque signals. This method is an indirect method to measure the thrust force and torque signals. The drilling test was conducted as per the plan of experiments and the parameters such as thrust force and torque were measured using Kistler multicomponent dynamometer 9257B type.
In this work, tool wear was measured using toolmakers microscope under laboratory conditions. From the preliminary test, we observed an increase in the cutting forces when the flank wear reached $0.3 \mathrm{~mm}$ for all drill bits; hence, a new tool was replaced when the flank wear has reached $0.3 \mathrm{~mm}$. The SEM image of the worn carbide drill used for the drilling process, the crosssectional view of the drilled hole of sample 2, and the SEM image of the drilled hole are shown in Figure 5B-D, respectively.

In industries, the selection of optimal cutting parameters based on handbook information may decrease the productivity and increase the manufacturing cost due to the suboptimal use of machining capability. The best possible use of the potential of the drilling process requires the mixture of a proper set of machining parameters [20].
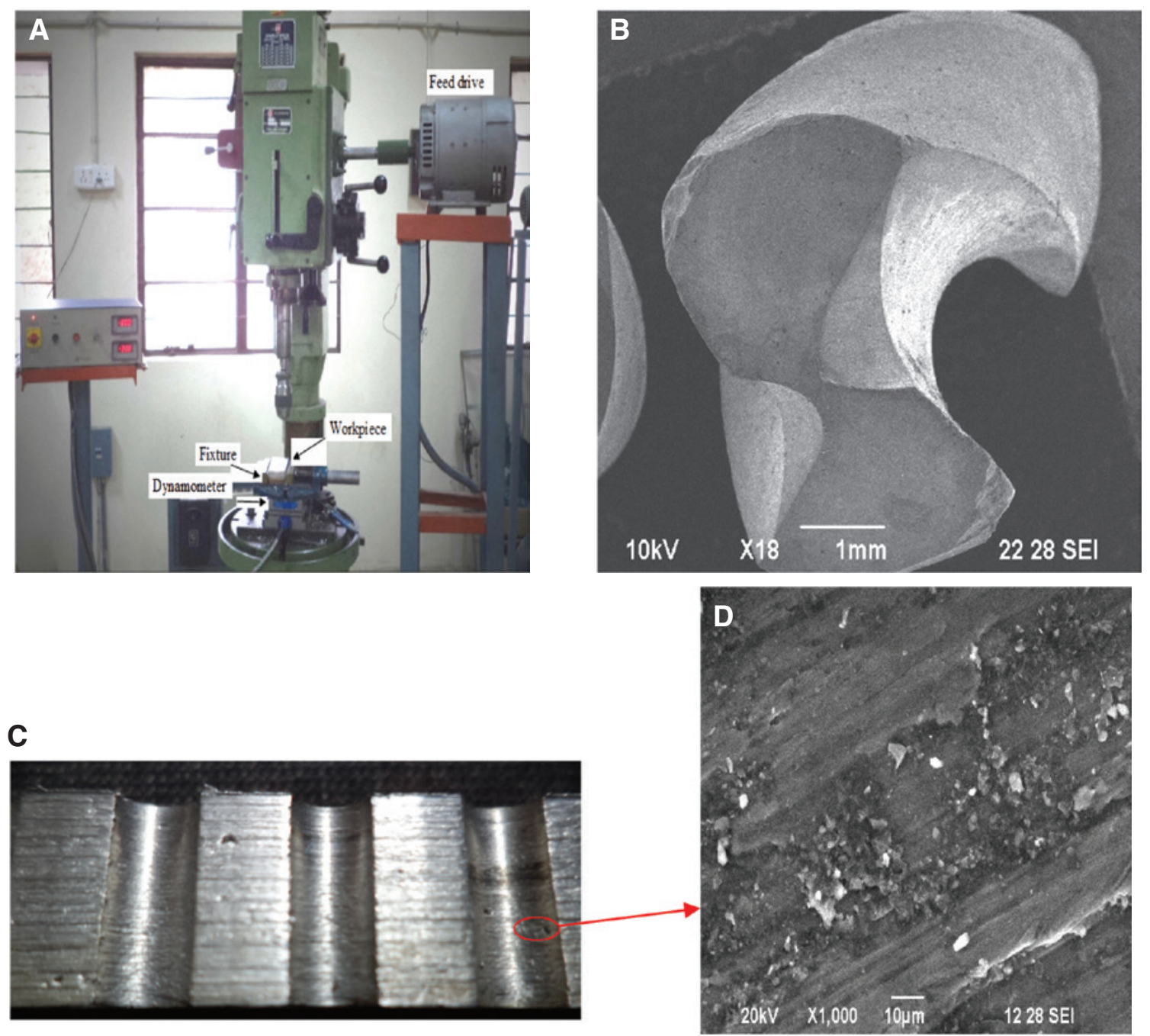

Figure 5: (A) Experimental set-up for thrust force and torque measurement, (B) SEM of the worn carbide drill bit at spindle speed $=1260 \mathrm{rpm}$ and feed $=0.03 \mathrm{~mm} / \mathrm{rev}$, (C) cross-sectional view of the drilled hole of sample 2, and (D) SEM image of the drilled hole using carbide drill at spindle speed $=1260 \mathrm{rpm}$ and feed $=0.03 \mathrm{~mm} / \mathrm{rev}$. 
Hence, there is a need for an optimization technique to solve the problem of improper selection of process parameters.

As the traditional experimental design method is complicated and time consuming, in this work, the Taguchi-based experimental design was applied to determine the optimal cutting parameters for minimum thrust force, torque, and tool wear. The experimental design with the Taguchi method uses a special design of orthogonal array, which is very simple and effective compared to the traditional experimental design method. The Taguchi method is a useful tool to study the entire process parameters for defining the experimental plan with only a small number of experiments [3, 20-23]. The major drawback with the Taguchi method is that it cannot judge and determine the effect of the individual parameter on the entire process. The results obtained cannot indicate the level of influence

Table 3: Control factors and their levels.

\begin{tabular}{lllll}
\hline Symbol & Control factors & Level 1 & Level 2 & Level 3 \\
\hline A & Prm & $10 \%$ & $20 \%$ & NIL \\
B & Drill type & HSS & Carbide & TiN-coated carbide \\
C & Spindle speed $(\mathrm{rpm})$ & 850 & 1260 & 1860 \\
D & Feed rate $(\mathrm{mm} / \mathrm{rev})$ & 0.03 & 0.05 & 0.07 \\
\hline
\end{tabular}

or highest effect of a particular parameter on the performance characteristic value.

However, the percentage contribution of individual parameters toward the response to be studied can be determined using ANOVA [11, 24]. Based on Taguchi's L18 $\left(2^{1} \times 3^{3}\right)$ orthogonal array mixed-level design, control factors such as percentage of reinforcement materials (Prm), drill type, spindle speed, and feed rate were selected and their levels are shown in Table 3. The levels and the limits used were determined from the preliminary experiments [25]. The responses to be studied are thrust force, torque, and tool flank wear.

The orthogonal array was selected by considering the following conditions: the number of degrees of freedom for orthogonal array must be greater than or equal to the number of degrees of freedom required for studying the main and interaction effects [26]. In this work, one factor at two levels and three factors at three levels and the interactions between Prmdrill type, Prmspindle speed, and Prm ${ }^{\star}$ feed rate are to be studied. The required degree of freedom is 11 . As the degrees of freedom for orthogonal array are greater than the number of degrees of freedom required for studying the main and interaction effects, an L18 orthogonal array was selected. Table 4 shows the experimental results of the measured values for thrust force, torque, and tool wear.

Table 4: Experimental results using L18 $\left(2^{1} \times 3^{3}\right)$ orthogonal array along with S/N ratio.

\begin{tabular}{|c|c|c|c|c|c|c|c|c|c|c|}
\hline \multirow{3}{*}{$\begin{array}{l}\text { Trail } \\
\text { no. }\end{array}$} & \multicolumn{4}{|c|}{ Control factors } & \multirow{3}{*}{$\begin{array}{r}\text { Thrust } \\
\text { force }(N)\end{array}$} & \multirow{3}{*}{$\begin{array}{r}\mathrm{S} / \mathrm{N} \text { ratio } \\
(\mathrm{dB})\end{array}$} & \multirow{3}{*}{$\begin{array}{r}\text { Torque } \\
(\mathrm{Nm})\end{array}$} & \multirow{3}{*}{$\begin{array}{r}S / N \text { ratio } \\
(\mathrm{dB})\end{array}$} & \multirow{3}{*}{$\begin{array}{r}\text { Tool wear } \\
(\mathrm{mm})\end{array}$} & \multirow{3}{*}{$\begin{array}{r}\text { Response } \\
\text { S/N ratio } \\
\text { (dB) }\end{array}$} \\
\hline & Prm & $\begin{array}{l}\text { Drill } \\
\text { type }\end{array}$ & $\begin{array}{r}\text { Spindle speed } \\
(\mathrm{rpm})\end{array}$ & $\begin{array}{l}\text { Feed rate } \\
(\mathrm{mm} / \mathrm{rev})\end{array}$ & & & & & & \\
\hline & (A) & (B) & (C) & (D) & & & & & & \\
\hline 1 & 1 & 1 & 1 & 1 & 156.6 & -43.8958 & 33.97 & -30.6219 & 0.121 & 18.3443 \\
\hline 2 & 1 & 1 & 2 & 2 & 201.32 & -46.0777 & 45.12 & -33.0874 & 0.195 & 14.1993 \\
\hline 3 & 1 & 1 & 3 & 3 & 293.50 & -49.3522 & 66.28 & -36.4276 & 0.310 & 10.1728 \\
\hline 4 & 1 & 2 & 1 & 1 & 145.20 & -43.2393 & 38.57 & -31.7250 & 0.112 & 19.0156 \\
\hline 5 & 1 & 2 & 2 & 2 & 162.12 & -44.1967 & 49.95 & -33.9707 & 0.151 & 16.4205 \\
\hline 6 & 1 & 2 & 3 & 3 & 233.70 & -47.3732 & 79.86 & -38.0466 & 0.287 & 10.8424 \\
\hline 7 & 1 & 3 & 1 & 2 & 207.90 & -46.3571 & 26.58 & -28.4911 & 0.148 & 16.5948 \\
\hline 8 & 1 & 3 & 2 & 3 & 265.48 & -48.4806 & 38.65 & -31.7430 & 0.208 & 13.6387 \\
\hline 9 & 1 & 3 & 3 & 1 & 178.95 & -45.0546 & 62.56 & -35.9259 & 0.328 & 9.6825 \\
\hline 10 & 2 & 1 & 1 & 3 & 348.15 & -50.8353 & 64.51 & -36.1925 & 0.133 & 17.5230 \\
\hline 11 & 2 & 1 & 2 & 1 & 218.40 & -46.7851 & 78.95 & -37.9470 & 0.231 & 12.7278 \\
\hline 12 & 2 & 1 & 3 & 2 & 245.00 & -47.7833 & 89.95 & -39.0800 & 0.322 & 9.8429 \\
\hline 13 & 2 & 2 & 1 & 2 & 225.65 & -47.0687 & 39.87 & -32.0129 & 0.120 & 18.4164 \\
\hline 14 & 2 & 2 & 2 & 3 & 340.30 & -50.6372 & 52.19 & -34.3517 & 0.196 & 14.1549 \\
\hline 15 & 2 & 2 & 3 & 1 & 179.00 & -45.0571 & 85.95 & -38.6849 & 0.302 & 10.3999 \\
\hline 16 & 2 & 3 & 1 & 3 & 385.20 & -51.7137 & 29.82 & -29.4902 & 0.165 & 15.6503 \\
\hline 17 & 2 & 3 & 2 & 1 & 235.00 & -47.4214 & 54.65 & -34.7518 & 0.228 & 12.8413 \\
\hline 18 & 2 & 3 & 3 & 2 & 297.20 & -49.4610 & 68.95 & -36.7707 & 0.362 & 8.8258 \\
\hline
\end{tabular}


Table 5: Response table for $\mathrm{S} / \mathrm{N}$ for thrust force.

\begin{tabular}{llrrr}
\hline Level & Prm & Drill type & Spindle speed & Feed rate \\
\hline 1 & $-46.00^{\mathrm{a}}$ & -47.45 & $-47.19^{\mathrm{a}}$ & $-45.24^{\mathrm{a}}$ \\
2 & -48.53 & $-46.26^{\mathrm{a}}$ & -47.27 & -46.82 \\
3 & NIL & -48.08 & -47.35 & -49.73 \\
Delta & 2.53 & 1.82 & 0.16 & 4.49 \\
Rank & 2 & 3 & 4 & 1 \\
\hline
\end{tabular}

${ }^{a}$ Optimal level.

Table 6: Response table for $\mathrm{S} / \mathrm{N}$ for torque.

\begin{tabular}{llrrr}
\hline Level & Prm & Drill type & Spindle speed & Feed rate \\
\hline 1 & $-33.34^{\mathrm{a}}$ & -35.56 & $-31.42^{\mathrm{a}}$ & -34.94 \\
2 & -35.48 & -34.80 & -34.31 & $-33.90^{\mathrm{a}}$ \\
3 & NIL & $-32.86^{\mathrm{a}}$ & -37.49 & -34.38 \\
Delta & 2.14 & 2.70 & 6.07 & 1.04 \\
Rank & 3 & 2 & 1 & 4 \\
\hline
\end{tabular}

${ }^{\mathrm{a} O p t i m a l}$ level.

Table 7: Response table for $\mathrm{S} / \mathrm{N}$ for tool wear.

\begin{tabular}{llrrr}
\hline Level & Prm & Drill type & Spindle speed & Feed rate \\
\hline 1 & $14.323^{\mathrm{a}}$ & 13.802 & $17.591^{\mathrm{a}}$ & 13.835 \\
2 & 13.376 & $14.875^{\mathrm{a}}$ & 13.997 & $14.050^{\mathrm{a}}$ \\
3 & NIL & 12.872 & 9.961 & 13.664 \\
Delta & 0.948 & 2.003 & 7.630 & 0.386 \\
Rank & 3 & 2 & 1 & 4 \\
\hline
\end{tabular}

aptimum level.

\subsection{Analysis of the signal-to-noise (S/N) ratio}

The experimental results were analyzed with the help of commercial software MINITAB 16. The influence of control factors on the response has been analyzed and the rank of involved factors, which support the $\mathrm{S} / \mathrm{N}$ ratio, is given in Tables 5-7.

Taguchi suggests the $\mathrm{S} / \mathrm{N}$ ratio to measure the quality characteristics [27]. Taguchi proposed three categories of performance characteristics in the analysis of the $\mathrm{S} / \mathrm{N}$ ratio: the smaller the better, the nominal the better, and the larger the better [7, 28]. As lowest values of thrust force, torque, and tool wear are considered to be optimal for high product quality, "the smaller the better" category was selected for the calculation of the $\mathrm{S} / \mathrm{N}$ ratio.

The optimum machining parameters for the responses, namely, thrust force, drilling torque, and tool wear, were found at the level where each factor has the highest $\mathrm{S} / \mathrm{N}$ ratio [20, 24-29]. It is clear from Table 5 that thrust force is lowest at the first level of Prm (A1), second level of drill type (B2), first level of the spindle speed (C1), and first level of feed rate (D1). The main effects plot of the $\mathrm{S} / \mathrm{N}$ ratio for thrust force shown in Figure 6A is also highest at these levels of the parameters, which result in the lowest thrust force. Hence, the combination of A1B2C1D1 (A1 =10\% of Prm, B2 = carbide drill, $\mathrm{C} 1=850 \mathrm{rpm}, \mathrm{D} 1=0.03 \mathrm{~mm} / \mathrm{rev}$ ) is considered to be optimal for lowest thrust force under the range of parameters investigated and also has the highest $\mathrm{S} / \mathrm{N}$ ratio. It is clear from the rank order of Table 5 that feed rate is having highest influence on thrust force followed by Prm, spindle speed, and drill type.

As the smaller the better category was selected for torque, from Table 6, the optimum level for minimum torque was found where each factor has the highest $\mathrm{S} / \mathrm{N}$ ratio as $\mathrm{A} 1 \mathrm{~B} 3 \mathrm{C} 1 \mathrm{D} 2(\mathrm{~A} 1=10 \%$ of $\mathrm{Prm}, \mathrm{B} 3=\mathrm{HSS}$ drill, $\mathrm{C} 1=850 \mathrm{rpm}, \mathrm{D} 2=0.05 \mathrm{~mm} / \mathrm{rev})$. The main effects of the $\mathrm{S} / \mathrm{N}$ ratio for torque shown in Figure $6 \mathrm{~B}$ are also highest at these levels of the parameters, which result in the lowest
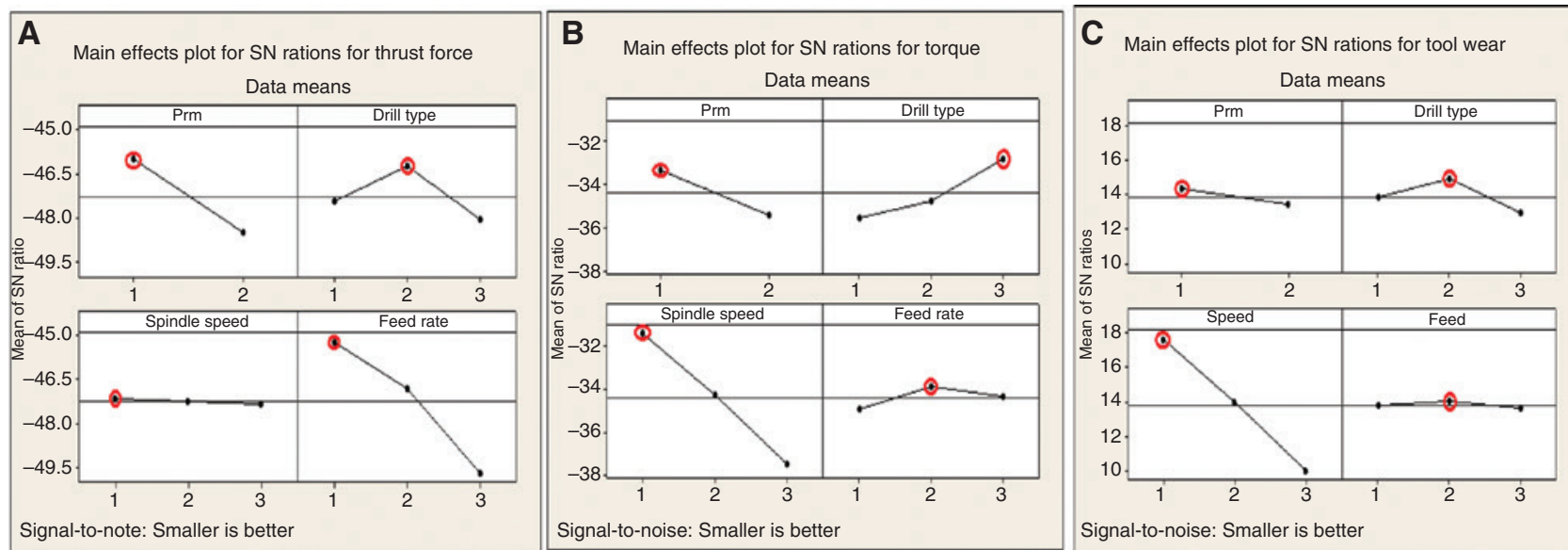

Figure 6: (A) Main effects plot for the $\mathrm{S} / \mathrm{N}$ ratio for thrust force, (B) main effects plot for the $\mathrm{S} / \mathrm{N}$ ratio for torque, and (C) main effects plot for the $\mathrm{S} / \mathrm{N}$ ratio for tool wear. 
torque. The rank order for torque shows that spindle speed is having the highest influence on torque followed by drill type, Prm, and feed rate. Similarly, from Table 7 and Figure 6C, the optimal levels for tool wear can be determined as A1B2C1D2 (A1 $=10 \%$ of Prm, B2 $=$ TiN-coated carbide drill, $\mathrm{C} 1=850 \mathrm{rpm}, \mathrm{D} 2=0.05 \mathrm{~mm} / \mathrm{rev})$.

\subsection{ANOVA method}

In this work, ANOVA was used to identify the optimum combination of process parameters by investigating the relative significance of factors in terms of their percentage contribution to the response [7, 11]. Apart from the significance of the control factors, the significance of interaction among the control factors on the response was studied as well. The interactions among control factors were between drill type and Prm $(B \times A)$, spindle speed and Prm $(C \times A)$, and feed rate and $\operatorname{Prm}(\mathrm{D} \times \mathrm{A})$.

The performed experimental plan was evaluated at a confidence level of $95 \%$. Table 8 presents the result of ANOVA for thrust force. The $\mathrm{R}^{2}$ value obtained for thrust force is $99.2 \%$, which is desirable [30]. It can be seen from Table 8 that the $\mathrm{p}$-value for Prm, drill type, and feed rate is $<0.05$, which indicates that the factors are statistically significant and have significant influence on the response (thrust force) [30, 31], whereas the p-value is $>0.05$ for spindle speed and for the interactions between the factors, which indicates that the spindle speed and interaction between the factors do not have any significant influence on thrust force. In addition to the p-value, Fisher's F-test can also be used to determine which machining parameters have a significant influence on the response. According to Fisher's F-test, if the calculated F-ratio value is more than the tabulated F-value, then the effect is considered as significant [2, 32]. In this work, the tabulated F-value for the drilling parameters is $(F 0.05,1,4=7.708)$ and $(\mathrm{F} 0.05,2,4=6.944)$ for the factor interactions. From ANOVA Table 8 for thrust force, it is clear that the F-test values for the feed rate, drill type, and Prm are greater than the F-table value, which indicate that they are statistically significant and have significant influence on the thrust force, whereas the F-test values for the spindle speed and factor interactions are smaller than the F-table values, which indicate that they are statistically insignificant. As the statistical significance of the spindle speed and for the factor interactions are minimum, they have negligible influence on the thrust force and can be neglected [33]. From the experimental results, it is clear that the feed rate has greater influence on the thrust force, coinciding with the findings of previous studies regarding the drilling of MMCs $[5,6,23,32,34]$. The order of the percentage contribution (\%) from ANOVA Table 8 reflects the relative importance of each factor in controlling the response, namely, thrust force. Among the four selected drilling parameters, feed rate has the highest contribution on thrust force $(59.77 \%)$ followed by Prm (27.58\%) and drill type $(9.84 \%)$. The interaction between the Prmspindle speed has $1.08 \%$, Prm ${ }^{\star}$ drill type has $0.58 \%$, and Prm ${ }^{\star}$ feed has $0.23 \%$ and finally spindle speed has $0.075 \%$ influence on thrust force.

Table 9 presents the results of ANOVA for torque. The $\mathrm{R}^{2}$ value of $96.9 \%$ was obtained from the ANOVA table, which is desirable [35]. It can be seen from Table 9 that Prm, drill type, and spindle speed have p-values $<0.05$, which indicate that they have significant influence on the response (torque) [30, 31], whereas the $p$-value is $>0.05$ for feed rate and for the interaction between the factors, which indicate that feed rate and the interaction between factors do not have any significant influence on torque. From ANOVA Table 9, it is clear that the calculated F-ratio value for the feed rate and factor interactions are less than the F-table values, which indicate that the feed rate and factor interactions are insignificant and they do not

Table 8: ANOVA for $\mathrm{S} / \mathrm{N}$ ratio for thrust force.

\begin{tabular}{|c|c|c|c|c|c|c|c|}
\hline Source & DF & Seq SS & Adj SS & Adjj MS & $\mathbf{F}$ & $\mathbf{p}$ & $\begin{array}{l}\text { Percentage } \\
\text { contribution }\end{array}$ \\
\hline Prm & 1 & 28.717 & 28.7167 & 28.7167 & 136.75 & 0.000 & 27.58 \\
\hline Drill type & 2 & 10.251 & 10.2510 & 5.1255 & 24.41 & 0.006 & 9.84 \\
\hline Spindle speed & 2 & 0.079 & 0.2514 & 0.1257 & 0.60 & 0.592 & 0.075 \\
\hline Feed rate & 2 & 62.234 & 42.5209 & 21.2605 & 101.24 & 0.000 & 59.77 \\
\hline Prm*drill type & 2 & 0.610 & 0.6097 & 0.3049 & 1.45 & 0.336 & 0.58 \\
\hline Prm*spindle speed & 2 & 1.132 & 1.1324 & 0.5662 & 2.70 & 0.181 & 1.08 \\
\hline Prm*feed rate & 2 & 0.244 & 0.2439 & 0.1220 & 0.58 & 0.601 & 0.23 \\
\hline Residual error & 4 & 0.840 & 0.8400 & 0.2100 & & & 0.81 \\
\hline Total & 17 & 104.107 & & & & & 100 \\
\hline
\end{tabular}


Table 9: ANOVA for $\mathrm{S} / \mathrm{N}$ ratios for torque.

\begin{tabular}{|c|c|c|c|c|c|c|c|}
\hline Source & DF & Seq SS & Adj SS & Adjj MS & $\mathbf{F}$ & $\mathbf{p}$ & $\begin{array}{l}\text { Percentage } \\
\text { contribution }\end{array}$ \\
\hline Prm & 1 & 20.571 & 20.5709 & 20.5709 & 14.85 & 0.018 & 11.64 \\
\hline Drill type & 2 & 23.209 & 23.2089 & 11.6045 & 8.38 & 0.037 & 13.13 \\
\hline Spindle speed & 2 & 110.513 & 71.1095 & 35.5548 & 25.67 & 0.005 & 62.55 \\
\hline Feed rate & 2 & 3.258 & 2.8798 & 1.4399 & 1.04 & 0.433 & 1.84 \\
\hline Prm*drill type & 2 & 12.165 & 12.1646 & 6.0823 & 4.39 & 0.098 & 6.88 \\
\hline Prm*spindle speed & 2 & 1.082 & 1.0818 & 0.5409 & 0.39 & 0.700 & 0.63 \\
\hline Prm*feed rate & 2 & 0.320 & 0.3202 & 0.1601 & 0.12 & 0.894 & 0.18 \\
\hline Residual error & 4 & 5.540 & 5.5399 & 1.3850 & & & 3.13 \\
\hline Total & 17 & 176.657 & & & & & 100 \\
\hline
\end{tabular}

have any significant influence on torque. It is clear from Table 9 that spindle speed is found to be the dominant parameter for torque and contributes $62.55 \%$ influence followed by drill type (13.13\%), Prm (11.64\%), and feed rate $(1.84 \%)$. The interaction between $\mathrm{Prm}^{\star}$ drill type has $6.88 \%, \mathrm{Prm}^{\star}$ spindle speed has $0.63 \%$, and $\mathrm{Prm}^{\star}$ feed rate has $0.18 \%$ influence on torque.

Table 10 presents the results of ANOVA for tool wear. Generally, tool wear is interrelated with many factors apart from the parameters taken for this investigation. Some of the parameters such as contact time between the nature of the tool and work piece and abrasive effects of the reinforced particles may also contribute to tool wear [11]. From ANOVA, the $\mathrm{R}^{2}$ value of $99.1 \%$ was obtained for tool wear, which is desirable [30]. The feed rate and the interaction between the parameters have $p$-values $>0.05$, which indicates that feed rate and the interactions between the parameters do not have any significant influence on the tool wear. In addition to the p-value, the F-test values for the feed rate and factor interactions are less than the F-table value, which indicates that they are statistically insignificant and have negligible influence on the tool wear. According to ANOVA Table 10, it is clear that spindle speed has greater influence on tool wear $(89.98 \%)$ followed by drill type (6.20\%), Prm (2.08\%), and feed rate $(0.23 \%)$. The interaction between $\mathrm{Prm}^{\star}$ spindle speed has $0.32 \%$, $\mathrm{Prm}^{\star}$ feed rate has $0.23 \%$, and Prm ${ }^{\star}$ drill type has $0.03 \%$ influence on tool wear.

\subsection{Multivariable linear regression analysis}

Regression analysis is a statistical tool used to find the relationship between the variables selected for investigation [36]. In this work, multivariable linear regression analysis was used to determine the correlations between the control factors (Prm, drill type, feed rate, and spindle speed), thrust force, torque, and tool wear. The standard commercial statistical software package MINITAB 16 was used to derive the regression equation of the form:

Thrust force $=-1.4+69.9 \mathrm{~A}+8.90 \mathrm{~B}-3.45 \mathrm{C}+62.8 \mathrm{D}$

$\mathrm{R}^{2}=0.854$.

Torque $=18.8+13.7 \mathrm{~A}-8.13 \mathrm{~B}+18.4 \mathrm{C}-19.5 \mathrm{D}$

$\mathrm{R}^{2}=0.867$.

Tool wear $=-0.0181+0.0221 \mathrm{~A}+0.0106 \mathrm{~B}+0.0927 \mathrm{C}$

$$
-0.00192 \mathrm{D}
$$

Table 10: ANOVA for $\mathrm{S} / \mathrm{N}$ ratios for tool wear.

\begin{tabular}{|c|c|c|c|c|c|c|c|}
\hline Source & DF & Seq SS & Adj SS & Adjj MS & $\mathbf{F}$ & p & $\begin{array}{l}\text { Percentage } \\
\text { contribution }\end{array}$ \\
\hline Prm & 1 & 4.041 & 4.041 & 4.0410 & 9.01 & 0.040 & 2.08 \\
\hline Drill type & 2 & 12.053 & 12.053 & 6.0265 & 13.44 & 0.017 & 6.20 \\
\hline Spindle speed & 2 & 174.832 & 115.005 & 57.5025 & 128.21 & 0.000 & 89.98 \\
\hline Feed rate & 2 & 0.449 & 0.304 & 0.1522 & 0.34 & 0.731 & 0.23 \\
\hline Prm*drill type & 2 & 0.054 & 0.054 & 0.0270 & 0.06 & 0.942 & 0.03 \\
\hline Prm*spindle speed & 2 & 0.616 & 0.616 & 0.3078 & 0.69 & 0.554 & 0.32 \\
\hline Prm*feed rate & 2 & 0.443 & 0.443 & 0.2215 & 0.49 & 0.643 & 0.23 \\
\hline Residual error & 4 & 1.794 & 1.794 & 0.4485 & & & 0.92 \\
\hline Total & 17 & 194.282 & & & & & 100 \\
\hline
\end{tabular}


In multiple linear regression analysis, $\mathrm{R}^{2}$ is the value of the correlation coefficient and should be between 0.8 and $1[5,37]$. In this work, the $\mathrm{R}^{2}$ statistic results indicate that the model is fitted and explains $85.4 \%, 86.7 \%$, and $92.75 \%$ of the variability for thrust force, torque, and tool wear, respectively. Figure 7A-B shows the normal probability plot for residuals for thrust force, torque, and tool wear during regression analysis. In this work, the residuals generally fall on a straight line, implying that the errors are normally distributed $[2,38,39]$.

\subsection{Confirmation experiment}

The confirmation experiment is highly recommended by Taguchi, and it is a crucial step to verify the experimental results $[7,20]$. In this work, the confirmation experiment was performed after identifying the optimum combination of the influential factors for cutting forces and tool wear.

The experiment was repeated three times to get the average value and the results were compared to the predicted values. The results of the confirmatory test are presented in Table 11. The predicted thrust force was found to be $145.65 \mathrm{~N}$ and the experimental value was $145.20 \mathrm{~N}$.
A good agreement between predicted and experimental values can be seen and the error was within $0.31 \%$. The predicted torque was found to be $24.56 \mathrm{Nm}$ and the experimental torque value was $25.35 \mathrm{Nm}$. A fair agreement was found between the predicted and measured torque values and the error was within $3.11 \%$. The predicted tool flank wear was found to be $0.114 \mathrm{~mm}$ and the experimental value was $0.115 \mathrm{~mm}$. A good agreement between predicted and experimental values can be seen and the error was within $0.86 \%$.

\section{Results and discussion}

\subsection{Analysis of cutting force signals}

Figures $8 \mathrm{~A}-\mathrm{F}$ and $9 \mathrm{~A}-\mathrm{F}$ show the measured typical thrust force and torque values of samples 1 and 2 using HSS drill, carbide, and TiN-coated carbide drill, respectively. The drilling process involves three stages, which are marked as I, II, and III in Figure 8A-F and 9A-F. During stage I of the drilling process, the chisel edge and the cutting lip of the drill perform the drilling operation and are fully engaged into the work piece. Also during stage I, the
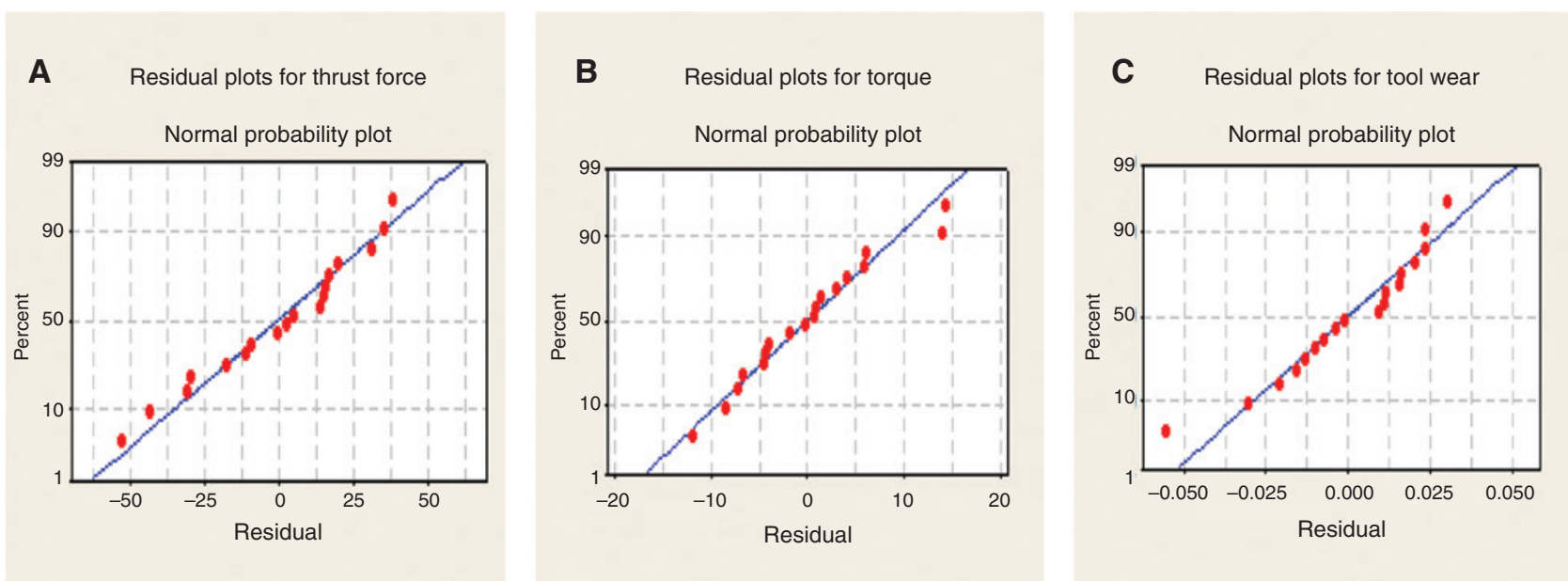

Figure 7: (A) Normal probability plot for thrust force, (B) normal probability plot for torque, and (C) normal probability plot for tool wear.

Table 11: Results of the confirmation experiment.

\begin{tabular}{|c|c|c|c|c|c|c|c|}
\hline \multirow[t]{2}{*}{ Test } & \multirow[t]{2}{*}{ Optimum levels } & \multicolumn{3}{|c|}{ Experimental value } & \multirow{2}{*}{$\begin{array}{r}\text { Average } \\
\text { experimental value }\end{array}$} & \multirow{2}{*}{$\begin{array}{l}\text { Predicted value from } \\
\text { the regression equation }\end{array}$} & \multirow[t]{2}{*}{$\%$ Error } \\
\hline & & Trail 1 & Trail 2 & Trail 3 & & & \\
\hline Thrust force (N) & $A(1), B(2), C(1), D(1)$ & 145.15 & 144.85 & 145.69 & 145.20 & 145.65 & 0.31 \\
\hline Torque (Nm) & $A(1), B(3), C(1), D(1)$ & 25.10 & 24.32 & 26.64 & 25.35 & 24.56 & 3.11 \\
\hline Tool wear $(\mathrm{mm})$ & $A(1), B(2), C(1), D(2)$ & 0.110 & 0.116 & 0.120 & 0.115 & 0.114 & 0.86 \\
\hline
\end{tabular}



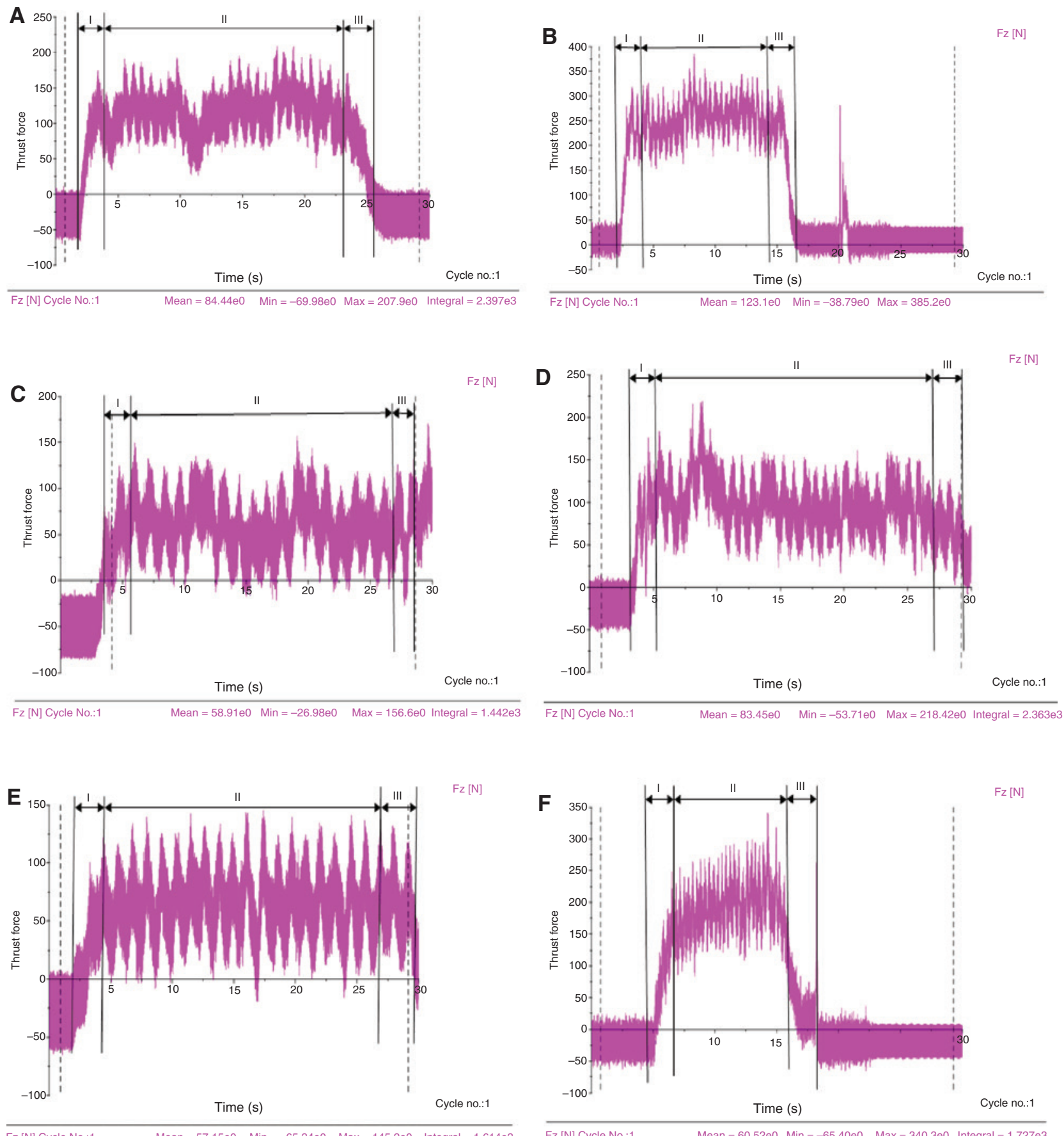

Figure 8: Typical thrust force values measured during preliminary test: (A) typical thrust force measured at spindle speed $=850 \mathrm{rpm}$, feed $=0.03 \mathrm{~mm} / \mathrm{rev}$, the work piece (10\% reinforcement), using HSS drill; (B) typical thrust force measured at spindle speed $=850 \mathrm{rpm}$, feed $=0.07 \mathrm{~mm} / \mathrm{rev}$, the work piece (20\%reinforcement), using HSS drill; (C) typical thrust force measured at spindle speed $=850 \mathrm{rpm}$, feed $=0.03 \mathrm{~mm} / \mathrm{rev}$, the work piece (10\% reinforcement), using carbide drill; (D) typical thrust force measured at spindle speed =1260 rpm, feed $=0.03 \mathrm{~mm} / \mathrm{rev}$, the work piece (20\%reinforcement), using carbide drill; (E) typical thrust force measured at spindle speed $=850 \mathrm{rpm}$, feed $=0.03 \mathrm{~mm} / \mathrm{rev}$, the work piece (10\% reinforcement), using TiN-coated carbide drill; and (F) typical thrust force measured at spindle speed $=1260 \mathrm{rpm}$, feed $=0.07 \mathrm{~mm} / \mathrm{rev}$, the work piece ( $20 \%$ reinforcement), using TiN-coated carbide drill.

thrust force and torque increase sharply. In stage II, the flutes of the drill also begin to cut and the drill tip reaches the bottom of the work piece. During stage II, the thrust force and torque reach the maximum value. Finally, during stage III, the drilling process is completed and the thrust force and torque decrease gradually because the chisel and cutting edges are gradually disengaged from the work piece. 

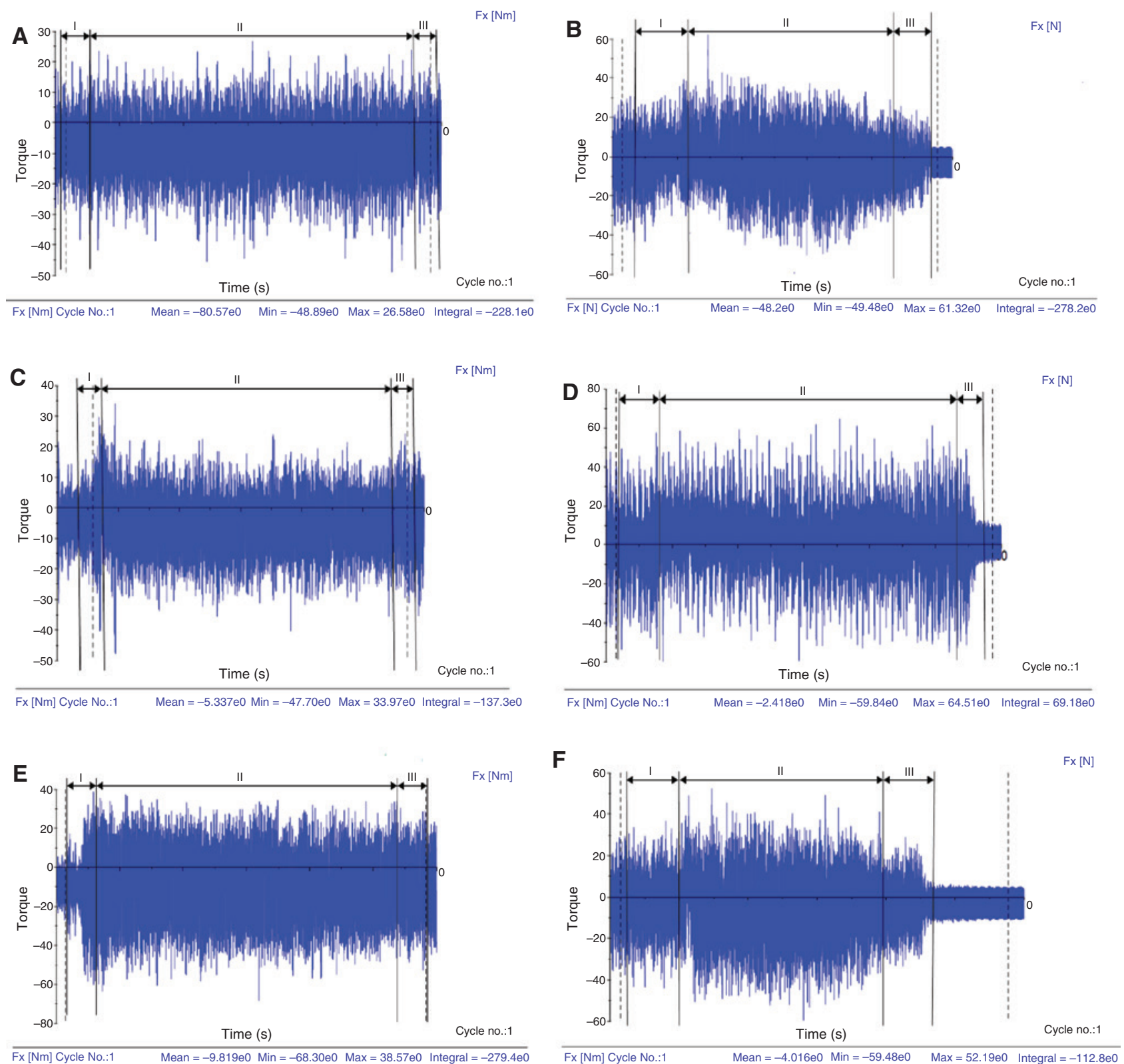

Figure 9: Typical torque values measured during preliminary test: (A) typical torque measured at spindle $\mathrm{speed}=850 \mathrm{rpm}, \mathrm{feed}=0.05 \mathrm{~mm} /$ rev, the work piece ( $10 \%$ reinforcement), using HSS drill; (B) typical torque measured at spindle speed $=1860 \mathrm{rpm}$, feed $=0.05 \mathrm{~mm} / \mathrm{rev}$, the work piece ( $20 \%$ reinforcement) using HSS drill; (C) typical torque measured at spindle speed $=850 \mathrm{rpm}$, feed $=0.03 \mathrm{~mm} / \mathrm{rev}$, the work piece (10\% reinforcement), using carbide drill; (D) typical torque measured at spindle speed $=850 \mathrm{rpm}$, feed $=0.07 \mathrm{~mm} / \mathrm{rev}$, the work piece $(20 \%$ reinforcement), using carbide drill; (E) typical torque measured at spindle speed $=850 \mathrm{rpm}$, feed $=0.03 \mathrm{~mm} / \mathrm{rev}$, the work piece (10\% reinforcement), using TiN-coated carbide drill; and (F) typical torque measured at spindle speed $=1260 \mathrm{rpm}$, feed $=0.07 \mathrm{~mm} / \mathrm{rev}$, the work piece (20\% reinforcement), using TiN-coated carbide drill.

\subsection{Analysis of thrust force signals}

On analyzing the thrust force signals of HSS drill, it clear that, during stage I of the drilling process, the thrust force reaches $175 \mathrm{~N}$ for sample 1 as shown in Figure 8A whereas, for sample 2, the thrust force increases sharply to $320 \mathrm{~N}$ as shown in Figure 8B. During stage II, the thrust force increases gradually and reaches a maximum value of
207.9 $\mathrm{N}$ for sample 1 and $385.2 \mathrm{~N}$ for sample 2. The drilling process is completed during stage III and the drill is completely disengaged from the work piece.

In case of carbide drill, during stage I, the thrust force was about $125 \mathrm{~N}$ for sample 1 as shown in Figure $8 \mathrm{C}$ and $170 \mathrm{~N}$ for sample 2 as shown in Figure 8D. In stage II, the thrust force was found to increase gradually and reaches 156.6 $\mathrm{N}$ for sample 1 and $218.4 \mathrm{~N}$ for sample 2. As the 
drilling process comes to an end during stage III, during this period, the thrust force decreases gradually and drops down to zero.

In case of TiN-coated carbide drill, during stage I, the thrust force was about $123 \mathrm{~N}$ for sample 1 as shown in Figure $8 \mathrm{E}$ and $220 \mathrm{~N}$ for sample 2 as shown in Figure 8F. During stage II, the thrust force increases gradually and reaches $145.2 \mathrm{~N}$ for sample 1 and the thrust force increases drastically and reaches $340.30 \mathrm{~N}$ for sample 2 . The thrust force increases drastically for sample 2 due to the increase in the tool wear caused by the chipping of the cutting edge at higher spindle speed and feed rate. From the experimental results, it was observed that the TiN-coated carbide drill has produced minimal thrust force when compared to the other drills taken for the investigation.

From the experimental results, it is clear that the thrust force increases drastically with the increase in the feed rate. This may be due to the fact that a higher feed rate creates a larger chip and the tool imparts a greater cutting force [40]. From ANOVA Table 8, it is clear that the feed rate is the most significant factor affecting the thrust force. Further, a higher thrust force was produced for HSS drills than with carbide and coated carbide drill particularly with higher particle fraction. This may be due to low hardness and the wear mechanism of the HSS drill bit [33].

It can also be seen that the thrust force tends to increase drastically with the increase in the reinforcement content, especially for sample 2, irrespective of the drills used, coinciding with the findings of [6]. The increase in the thrust force especially for sample 2 may be due to the increase in the hardness of the composite, increases the friction between the work piece and the tool, and intensifies the tool wear [33].

Further, from ANOVA Table 8, it is also clear that the spindle speed does not have any significant influence on the thrust force. Increasing the spindle speed from 850 to $1260 \mathrm{rpm}$ does not have any significant effect in reducing the thrust force, coinciding with the findings of [6]. Although there are former contradictory studies [32] stating that the thrust force decreases with the increase in the spindle speed, this effect is insignificant because, apart from the spindle speed, the contact time between the tool and the work piece, temperature, and abrasive effects of the reinforced particles play a vital role in tool wear. The combination of lower feed rate and lower spindle speed increases the contact time between the tool and the work piece, which in turn increases the tool wear. Further drilling with a worn tool increases the thrust force drastically [11].

Thus, from the experimental results, it is clear that the higher feed rate and the combined effect of lower feed rate with lower spindle speed have a major impact on increasing the thrust force drastically.

\subsection{Analysis of torque signals}

On analyzing the torque force signals of HSS drill, it can be seen that, during stage I of the drilling process, the torque reaches $20 \mathrm{~N}$ for sample 1 as shown in Figure 9A and $37 \mathrm{~N}$ for sample 2 as shown in Figure 9B. In stage II of the drilling process, the torque increases sharply and reaches a maximum value of $26.58 \mathrm{~N}$ for sample 1 and $61.32 \mathrm{~N}$ for sample 2. In stage III, the drilling process is completed and the drill is disengaged from the work piece.

In case of carbide drill, during stage I, the torque value reaches $29 \mathrm{~N}$ for sample 1 as shown in Figure $9 \mathrm{C}$ and $58 \mathrm{~N}$ for sample 2 as shown in Figure 9D. In stage II of the drilling process, the torque increases sharply and reaches a maximum value of $33.97 \mathrm{~N}$ for sample 1 and $64.51 \mathrm{~N}$ for sample 2, whereas, for TiN-coated carbide drill during stage I, the torque value increases sharply and reaches $39 \mathrm{~N}$ for sample 1 as shown in Figure 9E and $37 \mathrm{~N}$ for sample 2 as shown in Figure 9F. During stage II of the drilling process, the torque increases gradually and reaches a maximum value of $38.57 \mathrm{~N}$ for sample 1 and $52.19 \mathrm{~N}$ for sample 2.

The torque force generated by TiN-coated carbide drill is less than the carbide drill. This may be due to the presence of a protective coating that acts as a lubricant and reduces the friction and temperature at the cutting zone [4].

From ANOVA Table 9, it is clear that the spindle speed is the most significant factor influencing the torque. Drilling at a lower spindle speed is preferred over a higher spindle speed. However, there is a contradictory study [35], in opposition to our work stating that at lower spindle speed there is relatively more torque than at higher spindle speed. However, drilling at low spindle speed is not recommended for all types of materials. The spindle speed should be varied based on the work material, type of reinforcement, type of tool material, and the matrix.

There is one more work [8] stating that tool wear is very less at lower cutting speed. According to their work, the development of unstable build-up edge (BUE) caused by high contact time between the work piece and the tool protects the cutting edge from further wear. Further drilling with a worn tool would increase the cutting forces drastically.

From the experimental results, it can also be seen that the torque value increases significantly with the increase 
in the feed rate. The torque force generated by HSS drill is comparatively less than the carbide and TiN-coated carbide drill. This may be due to the fact that drill bit with smaller point angle exerts very less torque force on the work piece. The point angle of HSS drill used in this work is $118^{\circ}$ and $130^{\circ}$ for both carbide and coated carbide drill. According to previous studies [7, 41], the cutting torque increases with the increase in the point angle, correlating with our findings.

\section{Conclusions}

In this work, a drilling test was carried out using HSS, carbide, and TiN-coated carbide drills under dry conditions on the prepared AMMC. The AMMC was prepared by reinforcing Al6063 alloy with $10 \%$ and $20 \%$ weight fractions of WSD particles, an industrial waste generated during the rock stone dressing operation.

The cutting force and tool wear were recorded under different cutting conditions for various combinations of drilling parameters.

The following conclusions can be drawn from the study:

- Increasing the reinforcement content from $10 \%$ to $20 \%$ increases the hardness and tensile strength of the composites but reduces its ductility.

- The feed rate was identified as the most significant factor influencing the thrust force followed by Prm, drill type, and spindle speed.

- The torque and tool wear were strongly affected by the spindle speed followed by the drill type, Prm, and feed rate, respectively.

- From the experimental results, the composite with higher reinforcement content has higher thrust force, torque, and tool wear irrespective of the drills used for the investigation.

- Drilling with HSS drill has recorded the maximum thrust force value compared to the carbide and TiNcoated carbide drills, especially when drilling the composites with higher particle fractions.

- Drilling at very low spindle speed and feed rate increases the thrust force and torque drastically.

- Drill bit with smaller point angle is preferred over the larger one because HSS drill with $118^{\circ}$ point angle has produced less torque compared to $130^{\circ}$ point angle carbide and coated carbide drills.

- From the confirmation tests, a good approximation was achieved in the comparison of the predicted and the experimental results. Thus, the Taguchi design of experiments and ANOVA can be effectively used to identify the optimal level of the control factors to minimize the thrust force, torque, and tool wear.

\section{References}

[1] Dash K, Sukumaran S, Ray BC. Sci. Eng. Compos. Mater. 2016, 3,1-20.

[2] Palanikumar K, Muniaraj A. Measurement 2014, 53, 240-250.

[3] Basavarajappa S, Chandramohan G, Davim JP. J. Mater. Process. Technol. 2008, 196, 332-338.

[4] Davim JP. J. Mater. Process. Technol. 2003, 132, 250-254.

[5] Davim JP, Baptista AM. Proc. Inst. Mech. Eng. Pt. EJ. Process. Mech. Eng. 2001, 215, 177-183.

[6] Ramulu M, Rao PN, Kao H. J. Mater. Process. Technol. 2002, 124, 244-254.

[7] Taskesen A, Kütükde K. Mater. Technol. 2013, 47, 169-176.

[8] Francis Xavier L, Suresh P, Balaragavendheran R, Yeshwanth Kumar P, Deepak S. ARPN J. Eng. Appl. Sci. 2016, 11, 1277-1280.

[9] Chang SSF, Bone GM. Int. J. Mach. Tools Manuf. 2009, 49, 1070-1076.

[10] Rajmohan T, Palanikumar K, Davim JP. J. Mater. Sci. Technol. 2012, 28, 761-768.

[11] Taskesen A, Kutukde K. Trans. Nonferrous Met. Soc. China 2013, 23, 2524-2536.

[12] Davim JP, Baptista AM. J. Mater. Process. Technol. 2000, 103, 417-423.

[13] Park KH, Beal A, Kim D, Kwon P, Lantrip J. Wear 2011, 271, 2826-2835.

[14] Jantunen E. Int. J. Mach. Tools. Manuf. 2002, 42, 997-1010.

[15] Ghani JA, Rizal M, Nuawi MZ, Ghazali, Haron CHC. Wear 2011, 271, 2619-2624.

[16] Dimla Sr DE, Lister PM. Int. J. Mach. Tools. Manuf. 2000, 40, 739-768.

[17] Taskesen A, Kutukde K. Trans. Nonferrous Met. Soc. China 2015, 25, 271-283.

[18] Nagaral M, Auradi V, Ravishankar MK. Int. J. Res. Eng. Technol. 2013, 1, 193-198.

[19] Anilkumar HC, Hebbar HS, Ravishankar KS. Int. J. Mech. Mater. Eng. 2011, 6, 41-45.

[20] Tosun G. Int. J. Adv. Manuf. Technol. 2011, 55, 477-485.

[21] Haq AN, Marimuthu P, Jeyapaul R. Int. J. Adv. Manuf. Technol. 2008, 37, 250-255.

[22] Ay M, Altunpak Y. J. Eng. Fundam. 2015, 2, 42-50.

[23] Rajmohan T, Palanikumar K, Kathirvel M. Trans. Nonferrous Met. Soc. China 2012, 22, 1286-1297.

[24] Udaya Prakash J, Moorthy TV. Int. J. Appl. Eng. Res. 2015, 10, 526-529.

[25] Deng CS, Chin JH. Int. J. Adv. Manuf. Technol. 2005, 25, 420-426.

[26] Antony J, Preece D. Understanding, Managing and Implementing Quality. Frameworks Techniques and Cases. Routledge, London, 2002.

[27] Gaitonde VN, Karnik SR, Davim JP. J. Mater. Process. Technol. 2008, 196, 73-78.

[28] Navanth A, Karthikeya Sharma T. Int. J. Eng. Sci. Emerg. Technol. 2013, 6, 65-75. 
[29] Palanikumar K. Measurement 2011, 44, 2138-2148.

[30] Vinayagamoorthy R, Rajeswari N, Karuppiah B. Jourdan J. Mech. Ind. Eng. 2014, 8, 385-392.

[31] Campos Rubio JC, Silva LJD, Leite WDO, Panzera TH, Davim JP. Composites: Part B 2013, 55, 338-344.

[32] Munia Raj A. Int. J. Eng. Technol. 2014, 6, 2426-2434.

[33] Taskesen A, Kutukde K. Measurement 2013, 42, 321-330.

[34] Altunpak Y, Ay M, Aslan S, Int. J. Adv. Manuf. Technol. 2012, 60, 513-517.

[35] Munia Raj A, Manoharan N. Indian J. Sci. Technol. 2014, 7, 87-94.
[36] Mayyas A, Qasaimeh A, Alzoubi K, Lu S, Hayajneh MT, Hassan AM. J. Miner. Mater. Charact. Eng. 2012, 11, 1039-1049.

[37] Ficici F, Koksal MS, Karacadag C. Int. J. Sci. Adv. Technol. 2012, 23, 114-121.

[38] Vankanti VK, Ganta V. J. Mater. Res. Technol. 2014, 3, 35-41.

[39] Kyratsis P, Bilalis N, Antoniadis A. Comput.-Aided Des. 2011, 43, 1879-1890.

[40] Chandrashekhar S, Osman MOM, Sankar TS. Int. J. Prod. Res. 1984, 22, 697-721.

[41] Jayabal S, Natarajan U. Indian J. Eng. Mater. Sci. 2010, 17, 463-470. 